\title{
Radiation exposure in a group of interventional cardiologists in a high volume PCIcenter
}

Aims: To demonstrate differences in radiation doses between radial/femoral approach during cardiac catheterization. To increase awareness about ionizing radiation risks in the cath lab.

Methods: We measured radiation exposure in a group of interventional cardiologists between July and August 2017 in a high volume $\mathrm{PCl}$-center during 89 procedures. Four calibrated crystals (TLD 100) $3 \times 3 \times 0.89 \mathrm{~mm}$ were used to measure radiation: one in the middle of each ciliary region (crystalline exposition), thyroid (external to leaded protector) and chest (internal to the leaded apron). They were stored and transported in leaded containers to avoid contamination. They were analyzed daily with stimulated thermo-luminescence.

Results: Median fluoroscopy time was 4.24 minutes (IR 5.62) for radial access versus 6.02 minutes (IR 9.15) for femoral access ( $P=0.137)$. The median $\mathrm{mSv}$ in the entire body was $0.060 \mathrm{mSv}$ when access was radial vs. $0.054 \mathrm{msV}$ when access was femoral $(\mathrm{p}=0.949)$.

Conclusions: Femoral access was related with less radiation exposure in the past. Nowadays, radial access procedures are faster resulting on similar radiation exposure. Radial route could be more appropriate since it entails fewer complications for patients. This study measures crystalline dosimetry in front rather than laterally as most studies do, which undermines the real dose.

Keywords: Radiation exposure • Interventional cardiology • Coronary Artery • Grafting

Abbreviations: USA: United States of America; mSv: Milisievert; ACC: American College of Cardiology; SOLACI: Sociedad Latinoamericana de Cardiología Intervencionista - Latin-American Society of Interventional Cardiology; CABG: Coronary Artery Bypasses Grafting

\section{Introduction}

Interventional cardiology is the medical field in which operators are exposed to the highest ionizing radiation doses, compared with interventional radiologists or neuroradiologists [1]. In the USA, cardiologists represent $45 \%$ of the total cumulative effective dose of $3.0 \mathrm{mSV}$ per person per year (equivalent to the radiation from 150 chest X-rays) from all sources except radiotherapy [2].

Ionizing radiation may cause lesions in humans and animals such as dermatitis, alopecia, cataracts, retinal damage, burns and cancer. The most frequent malignant tumors related to ionizing radiation are brain, thyroid and skin cancer [3]. There is a concerning lack of adherence by interventional cardiologists to the use of protective equipment to reduce the effects of ionizing radiation. One study in Lithuania [4] showed that the lead thyroid collar, protective screen and leaded glasses were used in $93.5 \%, 83.9 \%$ and $35.5 \%$ of the cases, respectively. Many developing countries do not provide training on radioprotection topics at universities and health institutions where trainees rotate, and there is a lack of control and legislation from political parties, regulatory institutions and health centers to obligate these professionals to use the adequate radiological protection. In some cath labs a lead head protector has never been used.
Julio Cesar Rodriguez Goyes*1, Nicolas Jaramillo Gomez', Valentina Jaramillo Restrepo, Heidy Contreras², Jessica Villegas ${ }^{1}$, Willington Giraldo ${ }^{3}$, Juan Bedoya', Javier Morales ${ }^{3}$ and Eduardo Arias'

${ }^{1}$ Clínica Las Americas Medellín, Colombia ¿Universidad CES, Medellín, Colombia ${ }^{3}$ Universidad Nacional, Medellín, Colombia

*Author for correspondence: Tel.: +57(4) 3421010

Email: Julliusc@yahoo.com.mx Received date: June 01, 2018 Accepted date: June 25, 2018 Published date: July 16, 2018 
Radiological protective equipment may $b$ underused due to a lack of knowledge on this topi and/or the discomfort of wearing the equipment. Alsc the average elapsed time before developing a neoplasi in professionals exposed to ionizing radiation may $b$ too long, thus inducing a sense of calm and comfor In their article, Roguin et al. [5] showed that a perio of 12 to 32 years (average of 22 years) is needed $t$ develop brain cancer in people occupationally expose to ionizing radiation.

Industrialized countries have led the way in regulatin topics regarding ionizing radiation such as occupation: exposure doses and exposure monitoring and regulatio for workers, among others. Examples of the above ar The Euratom Law from Europe, the referral guideline for medical imaging from the European Commissior the American National Academy of Biological Science with its committee on biological studies on ionizin radiation (2006), the International Commissio on Radiological Protection (2007), and the Unite Nations Scientific Committee on the Effects of Atomi Radiation (2008) [2].

In 2005, the American College of Cardiolog (ACC) issued its interventional cardiology guideline and emphasized the responsibility of all doctors $t$ minimize procedural radiation-induced damages fo their patients, their coworkers and themselves [6]. I 2009, the science advisory from the American Hear Association Committee on Cardiac Imaging of th Council on Clinical Cardiology and the Committe on Cardiovascular Imaging and Intervention of th Council on Cardiovascular Radiology and Interventio issued the recommended doses for common exams $i$. . cardiology [7]. In 2010, the ACC disclosed the need for a proper and optimal use of radiological techniques in cardiology [8]. The Food and Drug Administration (FDA), in 2010, launched the initiative for reducing unnecessary radiation during medical tests [9].

One interesting Latin American publication is the article by Dr. Ariel Durán, who conducted a very innovative study evaluating 117 professionals during the 2011 SOLACI Congress. He took 99 exposed individuals and compared them against 18 nonexposed controls [10]. He found radiation-induced ocular pathology in $47 \%$ of the exposed population compared with $17 \%$ of those not exposed. Another study with a similar methodology analyzed doctors from Colombia, Uruguay and Malaysia and studied the risk of developing cataracts after occupational radiation exposure [11].

\section{Methods}

We measured the radiation exposure in a group of interventional cardiologists (three in total) who were well trained in radial access, between July and August 2017, at a high volume PCI-center (Clínica Las Américas, Medellín, Antioquia, Colombia) with standardized use of radiation protection methods, for a total of 89 procedures (both diagnostic and therapeutic). They were evaluated consecutively, based on patient assignation, and they performed various procedures (diagnostic, therapeutic, right sided, coronary intervention, and CABG evaluation) using diverse routes of access (radial, femoral, brachial, and conversion of radial to brachial or radial to femoral). There were neither TAVR procedures nor endovascular treatment of aortic aneurysms in this study.

Four $3 \times 3 \times 0.89 \mathrm{~mm}$ crystals (TLD $100 \mathrm{LiF}: \mathrm{MgTi}$ ) were used to measure radiation, calibrated before each measurement with metrological traceability. One was placed in the middle of each ciliary region (Figure 1), for indirect measurement of lens exposure, one on the thyroid (external to the leaded protector) and one on the chest (internal to the leaded apron). They were analyzed daily with stimulated thermoluminescence and afterwards underwent thermal treatment and were transported in leaded containers to avoid alteration in the measurements.

The angiography equipment was a Phillips ALLURA X-ray system. Quality control determined that its operation was correct, with satisfactory quality images (evaluated with the TOR CDR tool).

The radiological protection at the cath lab consisted of

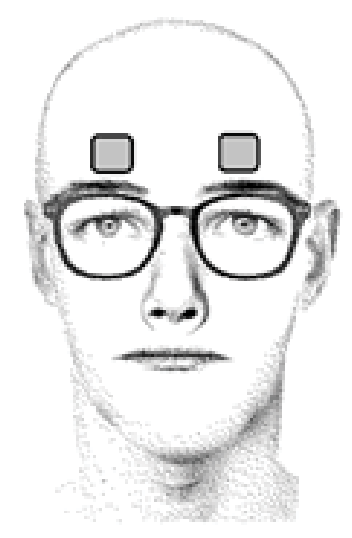

Figure 1. Location of cilliary dosymeters, note its central position on the cilliary region.

This figure was created with the Sketch Artist Male Free app from Android. 
a lead protective screen suspended in the air and a tabl curtain. All professionals always used the leaded apros and thyroid collar. Two cardiologists used protectiv eyewear all the time and one of them did not use lear glasses because he deemed them uncomfortable.

The crystals had a measurement range of $10 \mathrm{pGy}$ 100Gy and a HARSHAW 3500 reader was used. Th crystals were calibrated with metrological traceability The TLD crystals were distributed in all cases in group of three (packages).

Placing the dosimeters on the ciliary region (rathe than the lateral orbital edge, external to the latera canthus) provides a more reliable measurement becaus it is not influenced by the use of protective eyewear.

The crystals were thermally annealed with maximum temperature of $400^{\circ} \mathrm{C}$ before using them fo each measurement procedure. With this strategy, an residual information on the crystals was eliminated The crystals were transported and stored in a leader container, thus diminishing background radiation After using the crystals for each procedure, they wer stored again in the leaded container to diminish th "measurement fading" phenomenon. The crystals wer read within a two-day span, including the dosimeter used for natural background. After each reading, th crystals underwent thermal annealing again.

Error propagation was calculated for all th dosimeters used in each measurement (three for th present study), reader sensitivity and the propagatios of the calibration curve of the dosimeter-reading system.

\section{Statistical methods}

Continuous variables are expressed as mean (SD) or median (IQR). Categorical variables are expressed as percentages (\%) and numerics. Distribution of continuous variables was tested by Shapiro wilk test. Continuous variables for two independent groups were compared by Student's t test or Mann-Whitney U test depending on distribution pattern. All statistical tests were two-tailed, and $\mathrm{p}<0.05$ was considered statistically significant. All analyses were carried out in SPSS (version 21).

\section{Results}

Eighty-nine measurements on three interventional cardiologists were included in the present study. Each measurement represented a patient procedure varying from diagnostic to therapeutic interventions, and also classified by access route (radial, brachial, femoral or a mixture).

The interventional cardiologists performing the procedures had significant experience in the field. The median length of experience was 20 years and their average age was 56 years (Table 1).

Table 2 depicts the frequency of the procedures based on the route of access; it also shows the mean fluoroscopy time $(8.7 \mathrm{~min})$ and the average radiation dose $(0.054 \mathrm{mSv})$.

\begin{tabular}{|c|c|c|c|c|c|c|}
\hline Professional & Age (years) & $\begin{array}{l}\text { Experience } \\
\text { (years) as } \\
\text { Interventional } \\
\text { Cardiologist }\end{array}$ & $\begin{array}{c}\text { Use of lead } \\
\text { apron, thyroid } \\
\text { collar }\end{array}$ & Use of eyewear & $\begin{array}{c}\text { History of } \\
\text { benign disease } \\
\text { induced by } \\
\text { radiation }\end{array}$ & $\begin{array}{l}\text { History of } \\
\text { malign disease } \\
\text { induced by } \\
\text { radiation }\end{array}$ \\
\hline 1 & 61 & 22 & Always & No & No & No \\
\hline 2 & 53 & 20 & Always & Always & Yes* & No \\
\hline 3 & 56 & 19 & Always & Always & Yes* & No \\
\hline Median & 56 & 20 & & & & \\
\hline
\end{tabular}

*Both professionals are affected by alopecia on their legs.

\begin{tabular}{|cccc|}
\begin{tabular}{|c} 
Table 2. Frequency of the different routes of access \\
Route
\end{tabular} & Number of procedures & Mean fluoroscopy time (min) & Average HP10 (mSv) \\
\hline Brachial & 5 & 7.59 & 0.04 \\
\hline Radial & 50 & 5.11 & 0.06 \\
\hline Femoral & 30 & 7.3 & 0.07 \\
\hline Radial to femoral & 3 & 12.19 & 0.04 \\
\hline Radial to brachial & 1 & 11.35 & 0.06 \\
\hline Total / Mean & $\mathbf{8 9}$ & $\mathbf{8 . 7 0 8}$ & $\mathbf{0 . 0 5 4}$ \\
\hline
\end{tabular}

*Both professionals are affected by alopecia on their legs. 
Table 3. Detailed comparison of radiation exposure and procedure length when radial vs femoral approach used.

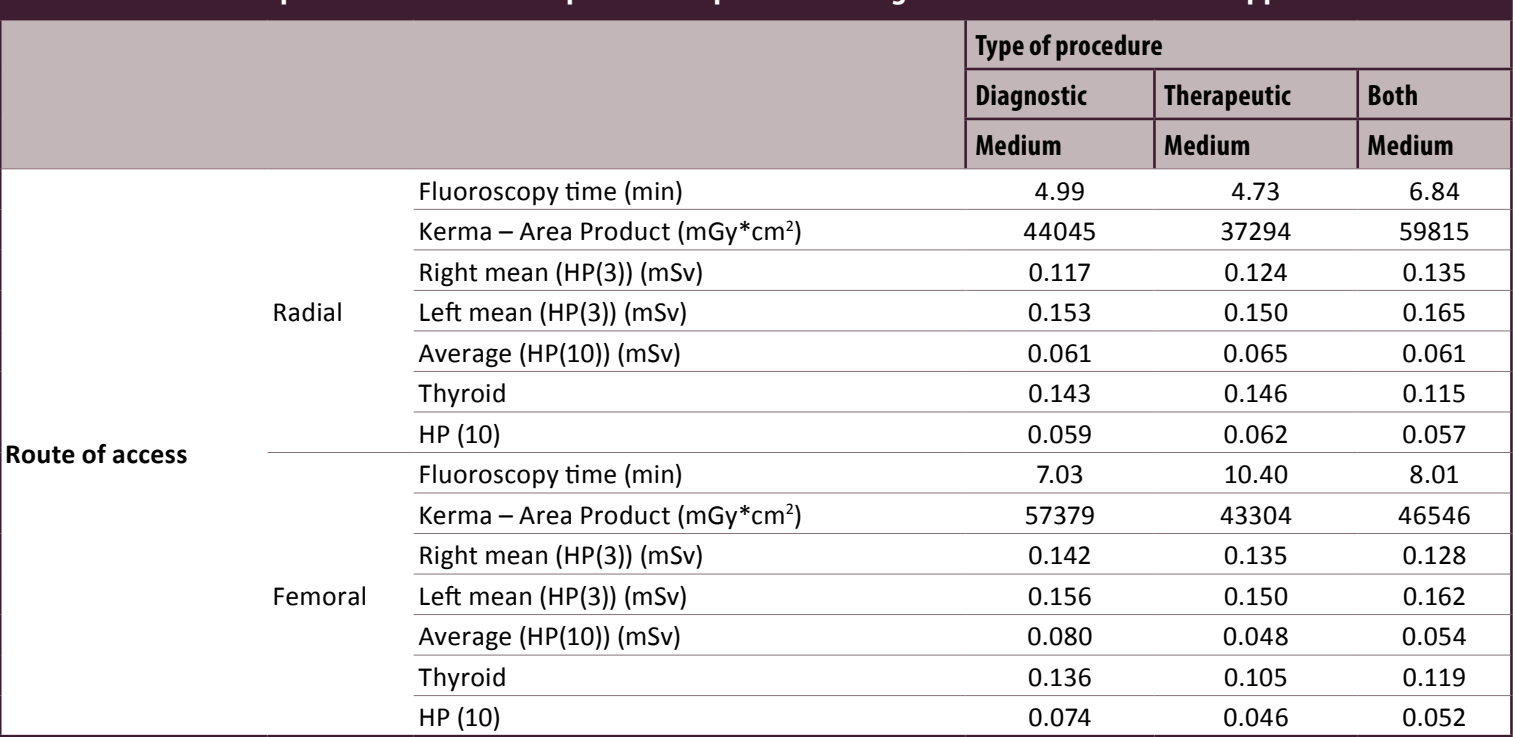

Table 3 compares the radial $v$ s. femoral approach, an also subclassifies each route according to whether th procedure was diagnostic, therapeutic or both. Media fluoroscopy time was 4.24 minutes (IR 5.62) for radia access versus 6.02 minutes (IR 9.15) for femoral acces $(\mathrm{p}=0.137)$. The median $\mathrm{mSv}$ in the entire body wa $0.06 \mathrm{mSv}$ with radial access vs. $0.054 \mathrm{mSc}$ with femora access $(\mathrm{p}=0.949)$.

\section{Discussion}

The current study is justified by the importanc of radiation exposure in interventional cardiolog laboratories. This topic is getting more importanc nowadays but there is still low awareness about it. I promotes unsafe practices by workers in the cath la affecting both of them and to the patients.

There is low concern regarding protection an exposure to ionizing radiation, it may explain the lor amount of research about this topic. In Latin Americ there are scarce number of publications and studies is this valuable field.

Recently the International Commission os Radiological Protection (ICRP) recommended reduction in the annual dose limit for occupationa exposure for the lens of the eye from 150 to $20 \mathrm{mS}$ averaged over a period of 5 years, with the dose in single year not exceeding $50 \mathrm{mSv}$.

The personal dose equivalent $\mathrm{Hp}$ [10] is now th internationally recommended operational quantit in the field of radiation protection by individua monitoring. It is the dose received by tissue (effectiv dose) at a $10 \mathrm{~mm}$ depth from the skin surface and is considered to be the dose to the whole body. The dose limit for workers proposed by the ICRP was established as an annual effective dose. An effective dose limit of $20 \mathrm{mSv}$ each year has been set for persons employed in radiation work.

The interventional cardiologists participating in this study and the radiation protection department of Clínica Las Américas (Medellín, Antioquia, Colombia) proposed an evaluation of the radiation dose both in crystalline and in total body. The aim was to objectively measure the radiation dose in these professionals and to check whether it was under the international standard limits.

89 interventional procedures from different categories and routes of access where included in the study. Fluoroscopy time and radiation dose where measured in each procedure and specially there was a comparison between radial and femoral access. This is the first time that a study of this type is done in Clínica Las Américas.

In interventional cardiology procedures, is widely known that femoral access is related with a higher rate of complications such as: hematomas, arteriovenous fistulae, pseudoaneurysms and bleeding in the site of access. Femoral route is also associated with a longer postoperative recovery, more immobility while deccanulation is done and with longer transit of patients in the interventional cardiology department (especially in ambulatory procedures). For the entire above, radial access is preferred over femoral route, unless there is a 
contraindication to be used.

In the group of interventional cardiologists evaluater there is no an agreement about the radiation protection tools nor its mandatory use. One of them does not us eyewear protection due to uncomfort. Two of the thre professionals routinely perform the procedures throug] radial access and the other one prefers the femoral rout $\epsilon$

This study showed no significant difference o1 radiation dose or length of procedures among thre interventional cardiologists when comparing radial $v$ : femoral access. This could let to suggest routine using o radial access supported also by many other advantage of this route discussed above. Increasing adherence $t_{1}$ radiation protection tools, especially eyewear protectios is critical. Professionals working in the cath lab mus standardize the routine use of a protective screen $t$, diminish cranial radiation and they may be advised $t$ use a leaded protective cap.

\section{Strengths and Limitations}

This study shows that there is no significant differenc in median fluoroscopy time ( $\mathrm{p}$ 0.137) or radiation dos ( $p$ 0.949) between radial and femoral approaches in th cath lab.

The strengths of this study include a homogeneou group of interventional cardiologists with a simila length of experience in the field. They had goor radial access skills which allowed them to perform th procedures in a reasonable amount of time, comparer with femoral access. In the past there was evidenc that the radial approach was linked to higher radiatiou exposure, but this could have been a consequence o the increased length of these procedures when radia access first began to be used worldwide. Over the pas 20 years, the difference in fluoroscopy time betwees radial and femoral access has dropped significantly $b$. almost $75 \%$ from 2 minutes in 1996 to 30 seconds is $2014(\mathrm{p}<0.0001)[12]$.

The study is limited by being observational, withou randomization or control. One of the interventional cardiologists never used protective eyewear due to comfort issues, as was his usual practice. This may not

\section{References}

1. Vaño E, González L, Guibelalde E, et al. Radiation exposure to medical staff in interventional and cardiac radiology. $\mathrm{Br} . \mathrm{J}$. Radiol. 71(849): 954-60 (1998).

2. Picano E, Vano E. The Radiation Issue in Cardiology: the time for action is now. Cardiovasc Ultrasound. 9: 35 (2011).

3. Ron E. Cancer risks from medical radiation. Health Phys. 85: 47-59 (2003). have influenced the validity of the study because the medium and supra ciliary crystals were located in an area outside the range of the lead glasses. One interventional cardiologist usually preferred to perform the procedures through the femoral access, which may undermine the validity of these results. The data obtained could conceivably persuade him to use the radial access as his preferred route, given that there are fewer complications for the patient with this access (principally the length of time the patient spends in the cath lab, decannulation time and bleeding complications).

\section{Conclusions}

We found a similar fluoroscopy time and radiation dose after comparing radial vs femoral access during conventional procedures in the cath lab. These findings may be applied to those interventional cardiologists with good experience in radial access. Non-expert professionals may have a higher radiation dose due to a more lengthy procedure via the radial approach. The data obtained in this study may be used to favor the generalized use of radial access since this route is linked to a lower frequency and severity of patient complications, early patient mobilization and a faster transit time through the cath lab.

\section{Impact on Daily Practice}

The use of radial access instead of femoral access, when possible, may help to increase the economical productivity of cath labs due to a speedy rotation of patients and fewer patient complications related to the procedure. Patients may benefit because they are able to be mobilized early after a radial access procedure, they can be discharged faster, and they would be expected to have a shorter immobilization time, which is associated with fewer thromboembolic complications. Radial access is also linked to fewer bleeding complications.

\section{Funding}

None

\section{Conflict of interest statement}

The authors have no conflict of interests to declare.

4. Zivile V, Martynas J, Inga C. Ionizing radiation exposure in interventional cardiology: current radiation protection practice of invasive cardiology operators in Lithuania. J Radiol Prot. 36: 695-708 (2016).

5. Roguin A, Goldstein J, Bar O, et al. interventional procedures. Am J Cardiol.

6. Brain and neck tumors among physicians performing 111:13681372 (2013). 
7. Hirshfeld JW, Balter S, Brinker JA, et al. ACCF/AHA/HRS/ SCAI Clinical competence statement on physician knowledge to optimize patient safety and image quality in fluoroscopically guided invasive cardiovascular procedures: a report of the american college of cardiology foundation/american heart association/american college of physicians task force on clinical competence and training. Circulation. 111: 511-532 (2005).

8. Gerber TC, Carr JJ, Arai AE, et al. Ionizing radiation in cardiac imaging: a science advisory from the American Heart Association Committee on Cardiac Imaging of the Council on Clinical Cardiology and Committee on Cardiovascular Imaging and Intervention of the Council on Cardiovascular Radiology and Intervention. Circulation. 119: 1056-65 (2009).

9. Brindis R, Douglas PS: President's page: The ACC encourages multipronged approach to radiation safety. J Am Coll Cardiol. 56: 522-4 (2010).

10. Food and Drug Administration White Paper: Initiative to
Reduce Unnecessary Radiation Exposure from Medical Imaging. Initiative to reduce unnecessary radiation exposure. [http:// www.fda.gov/Radiation-EmittingProducts/RadiationSafety/ RadiationDoseReduction/ucm199994.htm].

11. Solaci. Nearly half of interventional cardiologists may have precataract lesions | SOLACI. [online] Available at: http://solaci. org/en/2017/05/30/nearly-half-of-interventional-cardiologistsmay-have-pre-cataract-lesions/ (2017)

12. Kleiman N, Vano E, Duran A, et al. Risk for radiation cataract in Interventional Cardiology personnel. Invest Ophtalmol Vis Sci. 51: 4553 (2010).

13. Plourde G, Pancholy S, Nolan J, et al. Radiation exposure in relation to the arterial access site used for diagnostic coronary angiography and percutaneous coronary intervention: a systematic review of the literature and meta-analysis. Lancet. 386(10009): 2192-203 (2015). 